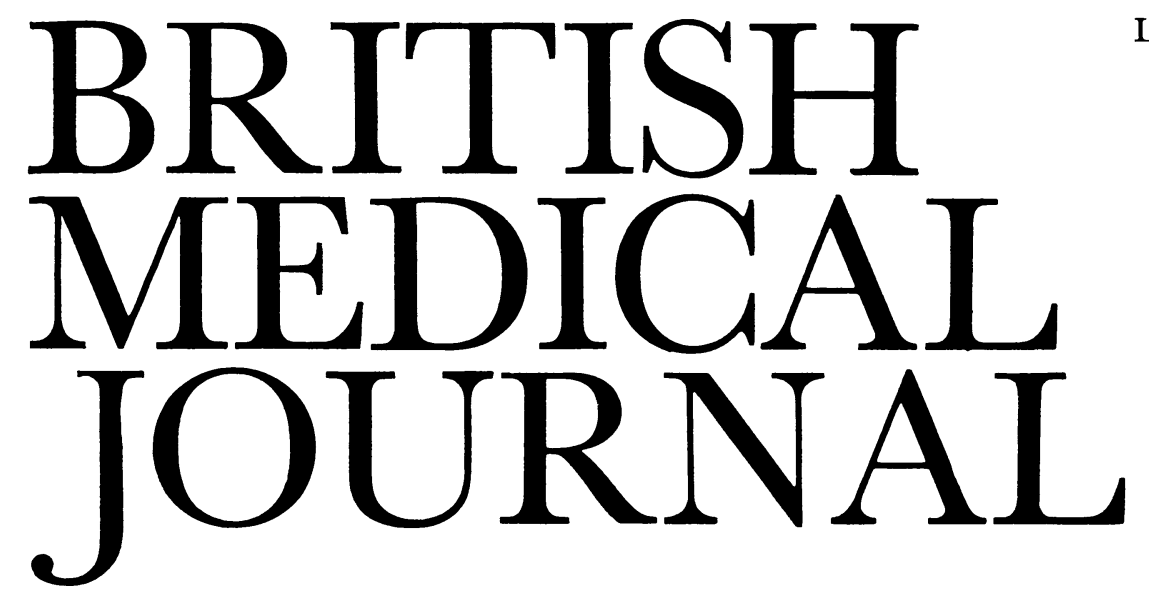

LONDON, SATURDAY 26 AUGUST 1978

\title{
Is cancer irreversible?
}

Evidence that cancer can remain latent goes back to the 1930s, though many clinicians and pathologists remained sceptical. Franks, ${ }^{1}$ who found many "incidental" latent cancers, particularly in the prostate, lung, kidney, and thyroid, described them as true cancers that were not developing or doing any harm. The preneoplastic lobules of the breast found in routine necropsies ${ }^{2}$ may come into the same category. Even established cancers-notably neuroblastomas, choriocarcinomas, teratomas, melanomas, and Burkitt's lymphomas-sometimes regress. ${ }^{34}$ The stability or otherwise of the neoplastic state (the subject of a symposium in the December 1977 issue of the American fournal of Pathology) could be an extremely fruitful idea in cancer research. If we understood why some lesions remain latent and some progress to cancer and why a few cancers regress we might be able to find new ways of preventing the irreversible disease-even after exposure to carcinogens.

At one time experimental work on the stages of carcinogenesis seemed little more than a laboratory game, relevant only to the skin of rabbits and mice. It may, however, help to explain the vagaries of human cancers and ultimately point to ways of interfering with their development. The idea that carcinogenesis occurs in two stages was first proposed by the Nobel laureate Peyton Rous in the 1940s. ${ }^{56}$ The first stage (tumour initiation) is a gene mutation or mutation-like change in individual body cells; the second stage (tumour promotion) by one of many mechanisms enables the genetically altered cell to proliferate to form a tumour. Carcinogens clearly are of many kinds-viruses of different types (in animals and probably in man), extremely diverse chemicals, and ionising radiations; but the discovery of the structure of DNA suggested the unifying principle: the distortion of the cell's genetic instructions that initiated the cancer process.

On this theory, then, in the first stage of carcinogenesis normal cells are converted irreversibly to latent cancer cells. ${ }^{7}$ Nevertheless, the effects of being exposed to a carcinogen experimentally may fade with time. ${ }^{8}$ Cells in which carcinogenesis has been initiated may be killed or shed; and if they have abnormal antigens on their surface, ${ }^{9}$ as a result of the change in their genetic material, they can probably be attacked by the immune surveillance system. ${ }^{10}$

If, however, the latent cancer cells are not lost they lie dormant for varying periods before giving rise to tumorous growths-or the animal may die before any tumour appears. On the other hand, a tumour-promoting substance or condi- tion might stimulate the dormant tumour cells; then they would multiply to form cancers prematurely. ${ }^{7}$ Indeed, in some circumstances an experimental tumour will persist only if the tumour promoter persists. The step from benign to malignant neoplasia may be a third stage of the carcinogenic process ${ }^{11}$ in fact, there may be a series of sudden steps whereby tumours become progressively more malignant. ${ }^{12}$ But, while some latent cells may have a highly malignant potential, others may have the potential only for benign tumour development. ${ }^{13}$

In animals a wide range of substances and conditions can promote cancer. Rous used both turpentine and wound healing as tumour promoters for rabbit skin. Numerous chemical substances (not only carcinogenic ones) have been found effective for the skin and other tissues of the mouse. ${ }^{14}$ Many other conditions, however, influence tumour development in animals exposed to carcinogens or carrying oncogenic viruses; they include the kind and amount of food ${ }^{1516}$ and hormonal, ${ }^{17}$ microbiological, ${ }^{18}$ and immunological ${ }^{19}{ }^{20}$ factors. Clinically, the concepts of initiating and promoting agents perhaps explain in part why only a proportion of people develop cancer after being exposed to a carcinogen. For example, smoking might promote the growth of tumours initiated in other ways ${ }^{14}$; this would explain why not all smokers develop lung cancer, why a few non-smokers do develop it, and why giving up smoking reduces the incidence.

The control of cancer becomes in some ways more and in some ways less difficult if tumour-promoting conditions are important in human cancer. On the one hand, the causation of tumours is then highly complex and some substances and conditions that are not by themselves carcinogenic, and would not appear so in simple tests, become "causes" of cancer when combined with other factors. ${ }^{14} 21$ On the other hand, tumour promotion might be easier to prevent or interfere with than tumour initiation: for instance, carcinogens are often recognised only after long delay, and an oncogenic virus that becomes incorporated in the cell material may offer little scope for attack-and indeed on its own may do little harm. Moreover, the actual processes of tumour promotion are likely to be more amenable to intervention than is the initial change in the cell.

Cancer research workers are increasingly recognising the importance of the tumour-promoting stage in carcinogenesis and a conference last year was devoted to the mechanisms. ${ }^{22}$ But clearly we must also exploit every opportunity to study No 6137 PAGE 585 
interacting factors through clinical and epidemiological investigations.

${ }^{1}$ Franks, L M, Annals of the Royal College of Surgeons, 1954, 15236.

2 Jensen, H M, Rice, J R, and Wellings, S R, Science, 1976, 191295.

${ }^{3}$ Evens, A W, Gerson, J, and Schnaufer, L, National Cancer Institute Monograph, 1976, 44, 49.

${ }^{4}$ McBurney, M W, American fournal of Pathology, 1977, 89, 685.

${ }^{5}$ MacKenzie, I, and Rous, P, fournal of Experimental Medicine, 1941, 73, 391.

${ }^{6}$ Friedewald, W F, and Rous, P, fournal of Experimental Medicine, 1944, 80, 101 .

${ }^{7}$ Bereblum, I, and Shubik, P, British fournal of Cancer, 1949, 3, 109 and 384.

${ }^{8}$ Roe, F J C, et al, International fournal of Cancer, 1972, 9, 264.

${ }^{9}$ Klein, G, in Scientific Foundations of Oncology, eds T Symington and R L Carter, p 497. London, Heinemann, 1976.

${ }^{10}$ Burnet, F M, Immunological Surveillance. Oxford, Pergamon Press, 1970.

11 Berenblum, I, Cancer Research, 1941, 1, 807.

12 Foulds, L, Cancer Research, 1965, 25, 1339.

13 Shubik, P, Cancer Research, 1950, 10, 713.

${ }^{14}$ Salaman, M H, and Roe, F J C, British Medical Bulletin, 1964, 20, 139.

15 Tannenbaum, A, Cancer Research, 1944, 4, 683.

${ }^{16}$ Roe, F J C, and Tucker, M J, Excerpta Medica International Congress Series, 1974, 311, 171.

17 Agnew, L R C, and Gardner, W U, Cancer Research, 1952, 12, 757.

18 Roe, F J C, and Grant, G A, International fournal of Cancer, 1970, 6, 133.

19 Allison, A C, and Law, L W, Proceedings of the Society of Experimental Biology (New York), 1965, 127, 207.

${ }^{20}$ Law, L W, Nature, 1965, 205, 672.

${ }^{21}$ Peraino, C, et al, Cancer Research, 1973, 33, 2701.

22 Slaga, T J, Sivak, A, and Boutwell, R K (eds), Mechanisms of Tumour Promotion and Carcinogenesis. New York, Raven Press, 1978.

\section{Patient package inserts}

To be successful, drug treatment needs co-operation from the patient, who must therefore have certain information about the drugs he is taking. The minimum information ${ }^{1}$ includes dosage, frequency of dose, and duration of treatment; whether the drug or drugs should be taken before, during, or after meals; whether alcohol, driving, or operating heavy machinery should be avoided; and whether there are any adverse effects requiring prompt action. Moreover, in an age when unquestioning acceptance of professional advice is being eroded (and doctors who dispute-or deprecate-this tendency should recall their own attitudes to accountants, solicitors, and their children's teachers) younger patients in particular may wish to know how their drugs work, how they will help their disease, why it is necessary to take them, and what adverse reactions might occur.

Traditionally, responsibility for telling patients about their drugs has rested primarily with the prescribing doctor, who has given the patient a verbal explanation and instructed the dispensing pharmacist to label the medicine bottle appropriately. This system, however, has drawbacks. Consultation times in general practice are little enough for an adequate history and physical examination. Patients remember only about half the information they are given during a consultation, ${ }^{2} 3$ and most of the forgetting takes place immediately. And, even if that unenlightening phrase "Take as directed" is excluded, patients' interpretations of apparently unambiguous labelling instructions (for example, "every six hours," "three times a day," "with meals") are erroneous in up to two-thirds of cases. ${ }^{4}$

In Britain patients receive written instructions about a few categories of drug. These include warning cards for those taking monoamine-oxidase inhibitors, systemic corticosteroids, and anticoagulants. Other cards have been produced by bodies such as the British Diabetic Association and the British Epileptic Association, and some drug manufacturers supply leaflets for patients with their products. In the United States of America the Food and Drugs Administration (FDA) requires printed material ("patient package inserts" or PPIs) to be provided for patients receiving oral contraceptives, intrauterine contraceptive devices, and oestrogens. The FDA is now under pressure from professional ${ }^{5}$ and consumer $^{6}$ organisations to extend PPIs to other (and ultimately nearly all) prescribed drugs. According to the present plan, ${ }^{78}$ the FDA would draw up PPIs (after consultation with interested parties), which would be issued to patients by the dispensing pharmacist at the same time as the prescribed drug. Doctors would retain the right, however, to prevent the patient from receiving a PPI by annotating the prescription accordingly. The information contained in the PPI would answer questions about why the drug is used, how it can help the patient, why it should be taken as directed, what adverse effects may develop, and what to do if these occur.

Inevitably, the PPI proposals have met with resistance. Critics argue, for example, that they would interfere with doctor-patient relationships, increase the tendency towards malpractice suits, pose considerable problems of production and distribution, ${ }^{910}$ and also possibly diminish, rather than enhance, patients' compliance by making them afraid of adverse reactions. Moreover, PPIs are likely to benefit a small minority of younger educated patients. Most of these doubts could be investigated by controlled trials, and the FDA is indeed conducting a study of PPIs for thiazides and methyldopa among hypertensive patients. ${ }^{7}$

In Britain there are no immediate plans for introducing PPIs, but the health professions are increasingly aware that patients need more information. Last month some 160 doctors, pharmacists, nurses, and health education officers took part in a symposium at Sheffield University on "Medicines, Information and the Patient"; and the DHSS and Medicines Commission are exploring ways of providing patients with information about drugs. These might include a more subtle approach to the medical consultation, ${ }^{11}$ counselling by the dispensing pharmacist, and better labelling of medicine bottles. A British equivalent of the PPI might well supplement these more traditional approaches, but which individuals taking which drugs would benefit? This is a problem needing carefully constructed randomised trials.

\footnotetext{
${ }^{1}$ Herxhe imer, A, Lancet, 1976, 2, 1294.

2 Ley, P, and Spelman, M S, British fournal of Social and Clinical Psychology, $1965,4,114$.

3 Joyce, C R B, et al, Quarterly fournal of Medicine, 1969, 38, 183.

4 Mazzullo, J M, Lasagna, L, and Griner, P F, fournal of the American Medical Association, 1974, 227, 929.

${ }^{5}$ Fleckenstein, L, Drug Information fournal, 1977, 11, 23.

${ }^{6}$ Cohen, M N, Drug Information fournal, 1977, 11, 34.

7 Morris, L A, and Gagliandi, V J, Drug Information fournal, 1977, 11, 17. ${ }^{8}$ Smith, K L, Drug Information fournal, 1977, 11, 30.

${ }^{9}$ Dorsey, R, fournal of the American Medical Association, 1977, 238, 1936.

${ }^{10}$ Ryan, K J, New England fournal of Medicine, 1977, 297, 1287.

11 Drug and Therapeutics Bulletin, 1973, 11, 81.
}

\section{The gate control theory of pain}

The gate control theory of pain sounds complex, but its principle is simple and has had wide practical consequences. Its essence is that signals which reach the spinal cord and are transmitted upwards to conscious sensation are modulated by 